\title{
EXOGENOUS APPLICATION OF MIXED MICRO-NUTRIENTS IMPROVES YIELD, QUALITY, AND 2-ACETYL-1-PYRROLINE CONTENTS IN FRAGRANT RICE
}

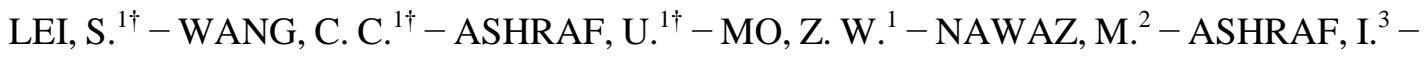 \\ MUZAFFAR, W. ${ }^{3}-$ LIU, S. J. ${ }^{1}-$ TANG, X. R. ${ }^{1 *}$ \\ ${ }^{I}$ Department of Crop Science and Technology, College of Agriculture, South China Agricultural \\ University, Guangzhou 510642, P. R. China \\ ${ }^{2}$ College of Agriculture, Hainan University, Haikou 570228, China \\ ${ }^{3}$ Department of Agronomy, University of Agriculture, Faisalabad 38040, Pakistan \\ ${ }^{\dagger}$ These authors have contributed equally to this work. \\ *Corresponding author: \\ e-mail: tangxr@scau.edu.cn; phonelfax:020-85280204-618 \\ (Received $30^{\text {th }}$ Dec 2016; accepted $24^{\text {th }}$ Mar 2017)
}

\begin{abstract}
Application of micro-nutrient at low concentrations can play significant roles in yield and quality improvements as well as aromatic characters of fragrant rice. Present study investigated the exogenous mixed application of micro-nutrients on yield quality, 2-acetyle-1-pyrroline (2-AP) and mineral content accumulation in the grains of two aromatic rice cultivars i.e., Xiangyaxiangzhan and Guixiangzhan. Two mixtures containing different proportions of micro-nutrients i.e., mixture-1 (40\% zinc sulfate, $6 \%$ manganese sulfate, $1 \%$ ferric chloride, $50 \%$ proline, and 3\% sodium selenite) and mixture-II (containing $1 \%$ gibberellic acid, $8 \%$ zinc sulfate, potassium $76 \%$ di-hydrogen phosphate, $8 \%$ manganese sulfate, and $7 \%$ copper sulfate) were exogenous applied at full heading stage at $1.5 \mathrm{~kg} \mathrm{hm}^{-2}$ (T1) and $3 \mathrm{~kg} \mathrm{hm}^{-2}$ (T2) diluted in $750 \mathrm{~L}$ water while plots with only water application were served as control (CK). Results revealed that exogenous application of mixed micro-nutrients notably increased yield in terms of improved grain numbers per panicle, filled grain (\%), 1000-grain weight, grain yield, grain 2-AP, selenium (Se) and zinc ( $\mathrm{Zn}$ ) contents while decreased amylose content, chalky rice percentage and chalkiness degree in both rice cultivars. Furthermore, exogenous application of mixed micro-nutrient enhanced above ground plant dry biomass for both rice cultivars. Significant correlations among 2-AP, $\mathrm{Zn}$ and $\mathrm{Se}(\mathrm{P} \leq 0.05)$ suggested that these two micro-nutrients have dynamic roles in rice aroma production, however, to unravel the exact mechanisms of micro-nutrient involvement in 2-AP biosynthesis, further research is needed.
\end{abstract}

Keywords: dry weight, rice aroma, nutrient concentration, grain chalkiness, amylose contents

\section{Introduction}

Fragrant rice (Oryza sativa L.) is precious for its special aroma, unique flavor and good quality (Baradi et al., 2015; Ashraf et al., 2017a,b). Thai 'jasmine' and Pak-Indian 'basmati' varieties are highly valued by consumers globally and gaining popularities in international markets (Huang et al., 2012), while the sale-price of aromatic rice is higher than non-aromatic rice (You et al., 2012). Through strumental analyses, it is well recognized that different volatile compounds involved in rice aroma formation (Champagne et al., 2005), of which 2-acetyl-1-pyrroline (2-AP) is a key 
aromatic compound (Mo et al., 2015; Li et al., 2016). The organic compounds extracted from different fragrant rice cultivars showed similar aroma profile, nevertheless the levels of different aroma compounds varied significantly (Maraval et al., 2008). Buttery et al. (1983) found 2-AP, (E)-2-nonenal, (E,E)-2,4-decadienal, 4-vinyl-guaiacol, 4-vinylphenol, hexanal, decanal and nonanal as principle compounds in the aroma of cooked rice. Furthermore, 2-AP is synthesized in both aromatic and non-aromatic rice cultivars; however, its level of production is quite lower in non-aromatic rice (Widjaja et al., 1996; Maraval et al., 2010).

Normally, plants absorb inorganic nutrients and metalic ions ions from soil solution through roots and transport them to different plant organs (Ashraf et al., 2015); however, the nutrient acquisition via roots is interdependent with nutrient assimilation rates in the leaves while efficacy of foliar applied nutrient uptake depends on plant architecture, canopy development and their mobility within the plant system (Saleem et al., 2010; Pandey et al., 2014; Hu et al., 2015). Foliar application of macro and micro-nutrients is more efficient than soil suppliemntation and led to significant increase in growth and yield of wheat (Zain et al., 2015). Exogenously applied micro-nutrients improved nutrient uptake, phenological events, growth and yield as well as grain micro-nutrient contents in cereals (Bameri et al., 2012). Recently, Habib et al. (2016) resulted that foliar applied nitric oxide improved growth and yield of rice. Micro-nutrient at low concentrations has significant roles in morphological growth, yield formation and quality characters of aromatic rice ( $\mathrm{Li}$ et al., 2016). For example, Tang and $\mathrm{Wu}$ (2006) found that $\mathrm{Zn}$ application (foliar or soil applied) could improve the growth and quality of aromatic rice. Tian et al. (2009) found that grain exogenous micro-nutrient application significantly increased seed setting rate and yield, while decreased percentage of chalkiness in rice grains. Except growth and yield, micro-nutrients could also improve rice aroma (Sun and Liu, 1991) by enhancing the biosynthesis of 2-AP in different plant parts of rice.

Most of the previous studies used micro-nutrients to evaluate their effectiveness on plant performance and grain quality (Fan et al., 2010; Wu et al., 2010); nevertheless information about the application of mixed micro-nutrients on the plant growth, yield and 2-AP contents in aromatic rice is very few. Thus, in this study, we used two different mixtures containing a set of micro-nutrients (zinc sulfate, manganese sulfate, ferric chloride, sodium selenite, potassium dihydrogen phosphate, and copper sulfate) along with proline, and gibberellic acid in different proportions to evaluate their effects on growth, yield and quality of fragrant rice. Furthermore, to provide additional insights on grain quality, 2-AP contents in grains and its relationships with applied micro-nutrients have also been studied.

\section{Materials and Methods}

\section{Experimental site and growing conditions}

This study was conducted in the Experimental Research Farm, South China

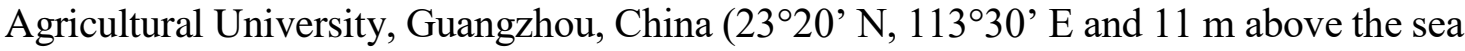


level. The climate is subtropical-monsoon type with mean annual air temperatures of 21.9 ${ }^{\circ} \mathrm{C}$, mean annual maximum and minimum air temperatures of $31.0^{\circ} \mathrm{C}$ (in June) and 15.0 ${ }^{\circ} \mathrm{C}$ (January), respectively (Fig. 1). The soil of the experimental site was lateritic red soil type containing $23.34 \mathrm{~g} \mathrm{~kg}^{-1}$ organic matter, $1.139 \mathrm{~g} \mathrm{~kg}^{-1}$ total $\mathrm{N}, 1.136 \mathrm{~g} \mathrm{~kg}^{-1}$ total $\mathrm{P}, 24.41$ $\mathrm{g} \cdot \mathrm{kg}^{-1}$ total $\mathrm{K}, 114.27 \mathrm{mg} \mathrm{kg}^{-1}$ available $\mathrm{N}, 61.34 \mathrm{mg} \mathrm{kg}^{-1}$ available $\mathrm{P}, 127.04 \mathrm{mg} \mathrm{kg}^{-1}$ available $\mathrm{K}$ and $6.45 \mathrm{pH}$.

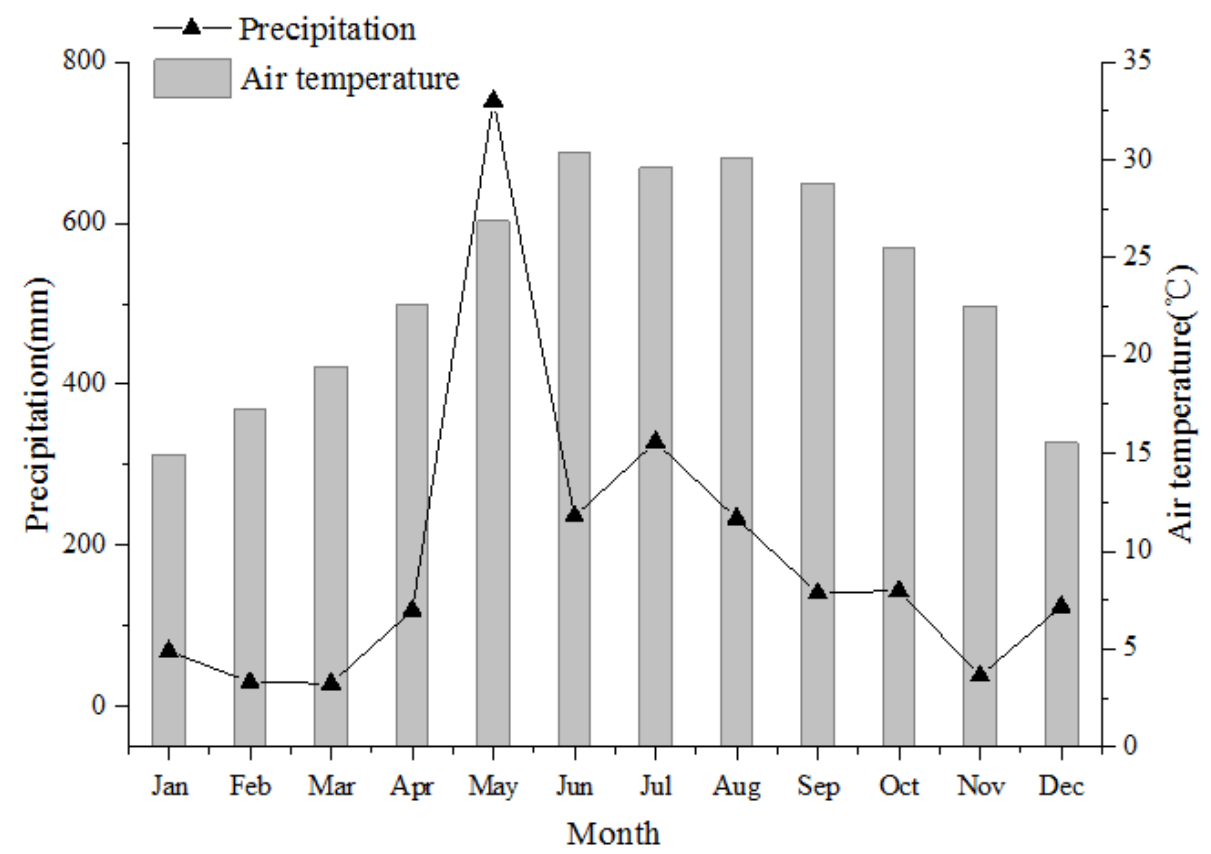

Figure 1. Mean monthly temperature and precipitation in 2015 of the experimental site

\section{Treatment application and crop husbandry}

Seeds of two aromatic rice cultivars i.e., Xiangyaxiangzhan and Guixiangzhan (famous due to their aroma and well adopted in South China) were collected from College of Agriculture, South China Agricultural University, Guangzhou China. Both cultivars have almost similar growth period ranging from 108 to 114 days from sowing to physiological maturity. Before sowing, seeds of both these cultivars were soaked in water for $24 \mathrm{~h}$ and allowed to germinate in dark chamber at $30^{\circ} \mathrm{C}$ for next $24 \mathrm{~h}$. Seeds of both rice cultivars were sown in the field (protected by plastic sheet) on March $12^{\text {th }}$ and transplanted on April $5^{\text {th }}, 2015$ at $20 \mathrm{~cm} \times 20 \mathrm{~cm}$ (hill to hill distance) with 4 seedlings per hill. At full heading stage, two micro-nutrient mixtures containing different proportions of micro-nutrients and growth and quality regulators were exogenously applied. Mixture-I containing $40 \%$ zinc sulfate, $6 \%$ manganese sulfate, $1 \%$ ferric chloride, $50 \%$ proline, and $3 \%$ sodium selenite and mixture-II containing $1 \% \mathrm{GA}_{3}, 8 \%$ zinc sulfate, potassium $76 \%$ di-hydrogen phosphate, $8 \%$ manganese sulfate, and $7 \%$ copper sulfate were obtained from 'Biotechnology Co., Ltd., Dongguan Foote, China'. Both mixture-I and mixture-II at $1.5 \mathrm{~kg} \mathrm{hm}^{-2}$ (T1) and $3 \mathrm{~kg} \mathrm{hm}^{-2}$ (T2) were diluted in 750 
L of water (as recommended by the company) and applied exogenously with the help of a special knapsack electric sprayer (3WBD-Qianfeng Agricultural machinery, Yangjiang, Guangdong, China) with $0.2-0.5 \mathrm{mPa}$ pressure and 16-18L capacity fitted with a special windproof atomizing spray nozzle was used for overhead spray. Both set of mixtures were manually sprayed in the evening (4 p.m.) with uniform movement in the treatment plots. In control $(\mathrm{CK})$ treatments, only water was sprayed exogenously at the same stage. A special fertilizer containing $12.5 \% \mathrm{~N}, 6 \% \mathrm{P}_{2} \mathrm{O}_{5}, 10 \% \mathrm{~K}_{2} \mathrm{O}$ and $15.0 \%$ organic matter was applied at $1500 \mathrm{~kg} \mathrm{ha}^{-1}$ with $60 \%$ as basal dose and $40 \%$ at tillering stage. All other standard agronomic practices were followed as recommended by the Guangdong Province, South China. The crop was harvested on July $6^{\text {th, }}$ tied into bundles, threshed and seeds were sun-dried for a week.

\section{Sampling and measurement}

\section{Determination of dry weight}

For the measurement of aboveground biomass, 3 plants were randomly sampled at 7 , 14 and 21 days after spraying (DAS), oven-dried at $80^{\circ} \mathrm{C}$ till constant weight. The dry weight of the plants was measured by using an electronic digital balance (BSA224S, Sartorius, Japan).

\section{Determination of grain quality and 2-AP contents}

Grain quality was measured after winnowing by NP-4350 winnower (Zhejiang, China). Brown rice rate was measured by rice husker (Jiangsu, China) while milled and head milled rice rates were measured by rice polishing machine (Zhejiang, China). The percentage of chalky grain and chalkiness degree were estimated by using a SDE-A light box (Guangzhou, China). Amylose protein content and alkali of rice grains were estimated by Infratec1241 grain analyzer (FOSS-TECATOR). For 2-AP contents, fresh grains (10 g) from each treatment were obtained and analyzed by synchronization distillation and extraction method (SDE) as devised by Mo et al. (2015).

\section{Determination of yield and yield related traits}

At maturity, an area of $5 \mathrm{~m}^{2}$ in each plot was reaped, threshed and sun dried to estimate grain yield and expressed as tons/square hectare meter $\left(\mathrm{t} \mathrm{hm}^{-2}\right)$. To measure grain numbers per panicle and seed setting rate five hills from each treatment were randomly sampled. From filled seeds lot, five random samples of 1000 grains were taken and weighed to record 1000-grain weight.

\section{Elemental analyses}

$\mathrm{Fe}, \mathrm{Zn}, \mathrm{Cr}$ and $\mathrm{Mn}$ content in grains were determined as described by Karanam (2011). Briefly, the dried samples of rice grains $(1 \mathrm{~g})$ were digested by $25 \mathrm{ml} 2 \mathrm{~mol} / \mathrm{L}$ HCL-Vitamin C mixture $(0.40 \mathrm{~g}$ Vitamin $\mathrm{C}$ dissolved in $834 \mathrm{ml}$ distilled water, then added $166 \mathrm{ml}$ concentrated $\mathrm{HCl}$ and mixed well). The concentration of $\mathrm{Fe}, \mathrm{Zn}, \mathrm{Cr}$ and 
$\mathrm{Mn}$ in the solution ware then measured by AA-650 Atomic Absorption Spectrometer (Shimadzu Company, Japan). Se content in grain was determined according to Zhang et al. (2014). Dried grain samples $(0.30 \mathrm{~g})$ were digested by $\mathrm{HNO}_{3}: \mathrm{HClO}_{4}(5: 1 \mathrm{v} / v)$ at 200

${ }^{\circ} \mathrm{C}$ for $1 \mathrm{~h}$ and diluted to $20 \mathrm{ml}$ with distilled water. The concentration of $\mathrm{Se}$ in the solution was measured by 8200 Atomic Fluorescence Spectrometer (JITIAN Company, China).

\section{Experimental design and data analyses}

The experiment was carried out in a randomized complete block design with three replications. The net plot size was $6 \mathrm{~m} \times 4 \mathrm{~m}$. Analysis of variance and correlation coefficients were performed using Statistix 8.0 (Analytical software, Tallahassee, Florida, USA) while the differences amongst treatments were separated by using least significant difference (LSD) test at $5 \%$ probability level.

\section{Results}

\section{Yield and yield related traits}

For Xiangyaxiangzhan, T1 caused a significant increment of seed setting rate and yield by $1.11 \%$ and $4.81 \%$ respectively. T2 resulted in a significant increment of grain numbers per panicle, 1000-grain weight and yield by $10.31 \%, 2.26 \%$ and $11.61 \%$ respectively. For Guixiangzhan, T1 significantly increased grain numbers per panicle and yield by $7.78 \%$ and $11.59 \%$ respectively. T2 significantly increased grain numbers per panicle, 1000-grain weight and yield by $5.72 \%, 4.20 \%$ and $10.26 \%$ respectively (Table 1).

Table 1. Effect of exogenous micro-nutrient application on yield and yield related traits of fragrant rice

\begin{tabular}{llllll}
\hline Rice cultivars & Treatment & $\begin{array}{l}\text { Grain numbers } \\
\text { per panicle }\end{array}$ & $\begin{array}{l}\text { Filled } \\
\text { grain } \\
(\%)\end{array}$ & $\begin{array}{l}\text { 1000-grain } \\
\text { weight } \\
(\mathrm{g})\end{array}$ & $\begin{array}{l}\text { Grain yield } \\
\left(\mathrm{t} \mathrm{hm}^{-2}\right)\end{array}$ \\
\hline \multirow{3}{*}{ Xiangyaxiangzhan } & CK & $122.10 \mathrm{~b}$ & $83.03 \mathrm{~b}$ & $19.87 \mathrm{~b}$ & $6.03 \mathrm{c}$ \\
& T1 & $124.60 \mathrm{~b}$ & $83.95 \mathrm{a}$ & $20.06 \mathrm{~b}$ & $6.32 \mathrm{~b}$ \\
& $\mathrm{~T} 2$ & $134.69 \mathrm{a}$ & $83.24 \mathrm{~b}$ & $20.32 \mathrm{a}$ & $6.73 \mathrm{a}$ \\
Guixiangzhan & $\mathrm{CK}$ & $111.48 \mathrm{c}$ & $82.44 \mathrm{a}$ & $22.14 \mathrm{~b}$ & $6.04 \mathrm{~b}$ \\
& $\mathrm{~T} 1$ & $120.15 \mathrm{a}$ & $82.98 \mathrm{a}$ & $22.38 \mathrm{~b}$ & $6.74 \mathrm{a}$ \\
& $\mathrm{T} 2$ & $117.86 \mathrm{~b}$ & $82.32 \mathrm{a}$ & $23.07 \mathrm{a}$ & $6.66 \mathrm{a}$ \\
\hline
\end{tabular}

Values sharing a letter in common within a column do not differ significantly according to LSD test at $\mathrm{P}<0.05$. CK (control); T1 (40\% zinc sulfate, $6 \%$ manganese sulfate, $1 \%$ ferric chloride, $50 \%$ proline, and $3 \%$ sodium selenite), T2 (1\% gibberellic acid, $8 \%$ zinc sulfate, potassium $76 \%$ di-hydrogen phosphate, $8 \%$ manganese sulfate, and $7 \%$ copper sulfate). 


\section{Grain quality attributes}

For Xiangyaxiangzhan, T1 significantly increased protein content by $7.45 \%$. T1 and T2 significantly decreased amylose content, percentage of chalky rice and chalkiness degree. For Guixiangzhan, T1 significantly increased protein content by $8.38 \%$. T1 and $\mathrm{T} 2$ resulted in a decrease of amylose content, percentage of chalky rice and chalkiness degree (Table 2).

Table 2. Effect of exogenous micro-nutrient application on grain quality of fragrant rice

\begin{tabular}{llllll}
\hline Rice cultivars & Treatment & $\begin{array}{l}\text { Protein } \\
\text { content } \\
(\%)\end{array}$ & $\begin{array}{l}\text { Amylose } \\
\text { content } \\
(\%)\end{array}$ & $\begin{array}{l}\text { Chalky rice } \\
(\%)\end{array}$ & $\begin{array}{l}\text { Chalkiness } \\
\text { degree }\end{array}$ \\
\hline Xiangyaxiangzhan & $\mathrm{CK}$ & $9.43 \mathrm{~b}$ & $19.27 \mathrm{a}$ & $5.12 \mathrm{a}$ & $0.44 \mathrm{a}$ \\
& $\mathrm{T} 1$ & $10.13 \mathrm{a}$ & $18.33 \mathrm{~b}$ & $2.89 \mathrm{c}$ & $0.16 \mathrm{c}$ \\
& $\mathrm{T} 2$ & $9.47 \mathrm{~b}$ & $18.03 \mathrm{c}$ & $3.69 \mathrm{~b}$ & $0.25 \mathrm{~b}$ \\
Guixiangzhan & $\mathrm{CK}$ & $8.83 \mathrm{~b}$ & $19.10 \mathrm{a}$ & $5.54 \mathrm{a}$ & $0.38 \mathrm{a}$ \\
& $\mathrm{T} 1$ & $9.57 \mathrm{a}$ & $17.93 \mathrm{~b}$ & $3.11 \mathrm{~b}$ & $0.14 \mathrm{~b}$ \\
& $\mathrm{~T} 2$ & $8.87 \mathrm{~b}$ & $17.47 \mathrm{c}$ & $2.77 \mathrm{c}$ & $0.07 \mathrm{c}$ \\
\hline
\end{tabular}

Values sharing a letter in common within a column do not differ significantly according to LSD test at $\mathrm{P}<0.05$. CK (control); T1 (40\% zinc sulfate, $6 \%$ manganese sulfate, $1 \%$ ferric chloride, $50 \%$ proline, and $3 \%$ sodium selenite), T2 (1\% gibberellic acid, $8 \%$ zinc sulfate, potassium $76 \%$ di-hydrogen phosphate, $8 \%$ manganese sulfate, and $7 \%$ copper sulfate).

\section{Dry matter accumulation}

For Xiangyaxiangzhan, T1 caused a significant increment of population dry matter accumulation by $13.21 \%, 22.77 \%$ and $21.87 \%$ at $7 \mathrm{~d}, 14 \mathrm{~d}$ and $21 \mathrm{~d}$ after treatment respectively. T2 significantly increased population dry matter accumulation by $9.61 \%$ at $21 \mathrm{~d}$ after treatment. For Guixiangzhan, T1 significantly increased population dry matter accumulation by $10.51 \%, 18.55 \%$ and $11.49 \%$ at $7 \mathrm{~d}, 14 \mathrm{~d}$ and $21 \mathrm{~d}$ after treatment respectively. T2 significantly increased population dry matter accumulation at $7 \mathrm{~d}, 14 \mathrm{~d}$ and $21 \mathrm{~d}$ after treatment, increased by $10.51 \%, 18.55 \%$ and $11.49 \%$ respectively (Table 3 ).

\section{Grain 2-AP and nutrient acquisition}

Both T1 and T2 significantly improved grain 2-AP contents by $94.32 \%$ and $61.69 \%$ in Xiangyaxiangzhan and upto $37.44 \%$ and $44.01 \%$, in Guixiangzhan respectively compared with control (Fig. 2a). Both cultivars showed a similar response to both set of nutrient mixtures in accumulation of grain Se content. T1 and T2 increased Se contents in the grains for both cultivars considerably. Moreover, T1 showed the highest Se content in grains for both cultivars, with $0.17 \mathrm{mg} \mathrm{kg}^{-1}$ and $0.16 \mathrm{mg} \mathrm{kg}^{-1}$, respectively (Fig. 2b). Exogenous micro-nutrient application enhanced grain Fe contents for both rice cultivars. T1 led to 0.79 and $1.56 \%$ higher grain Fe contents in Xiangyaxiangzhan and Guixiangzhan, respectively while T2 found statistically similar to CK (only water spray) (Fig. 2c). 
a)

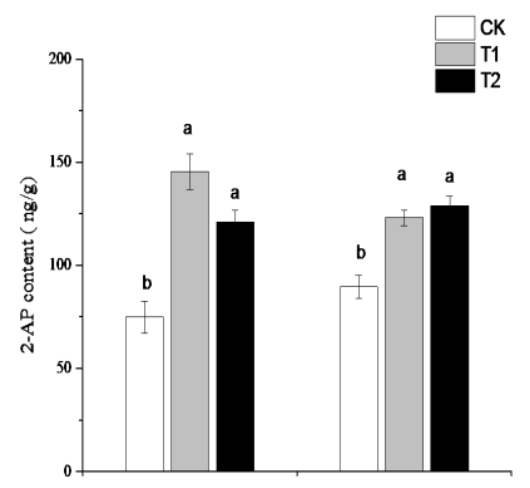

b)

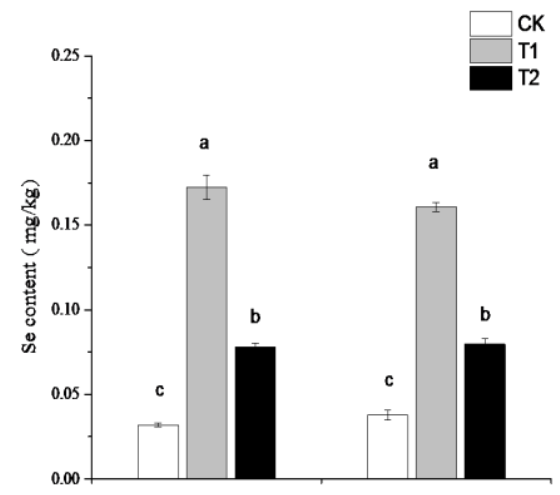

c)

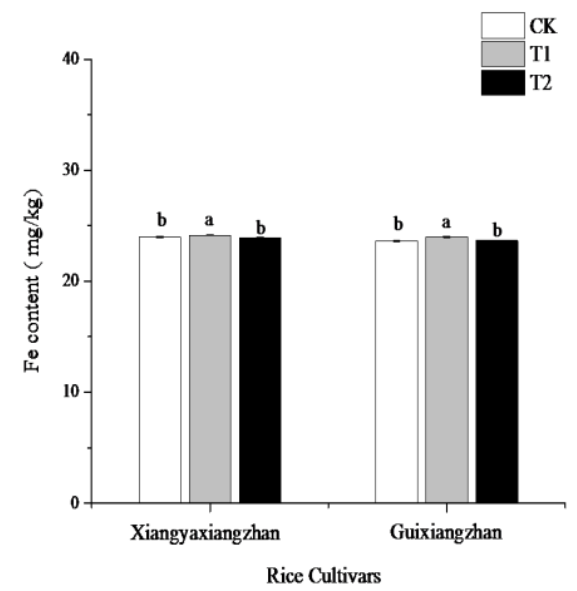

d)

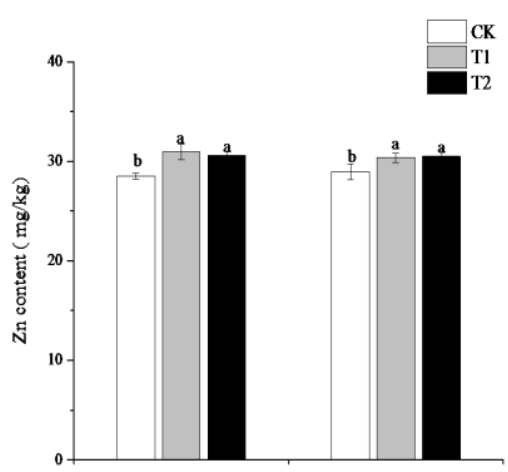

e)

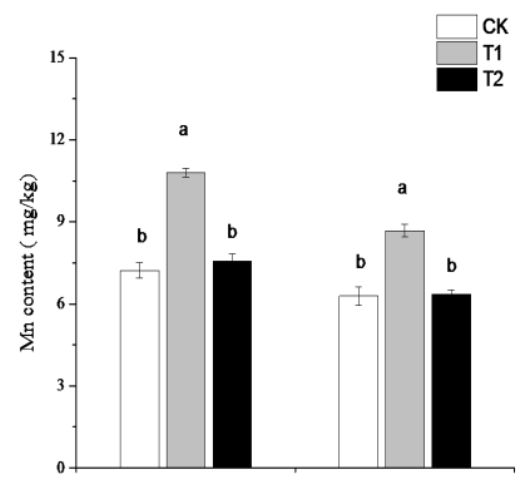

f)

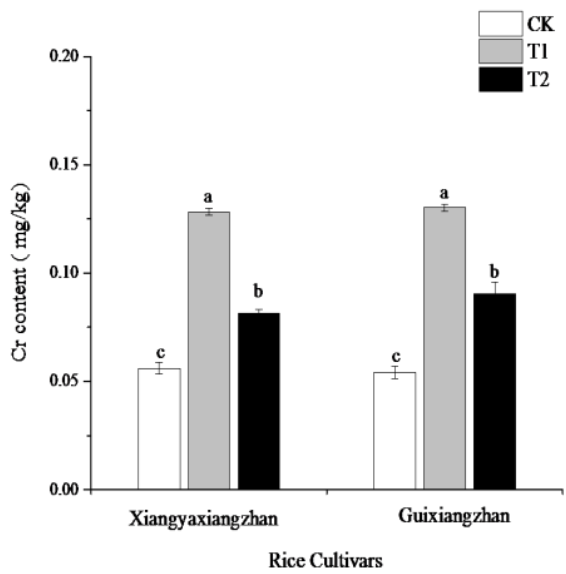

Figure 2. Effects of exogenous micro-nutrient application on grain a) 2-acetyle-1-pyrroline $(2-\mathrm{AP})$, b) Selenium (Se), c) Iron ( $\mathrm{Fe}), d)$ zinc ( $\mathrm{Zn})$, e) Manganese ( $\mathrm{Mn})$, and f) chromium ( $\mathrm{Cr}$ ) contents in two aromatic rice cultivars. Means with different lowercase letters differ significantly according to $L S D$ test at $P<0.05$. Capped bars represent $S D$ of three replications. CK (control); T1(40\% zinc sulfate, $6 \%$ manganese sulfate, $1 \%$ ferric chloride, $50 \%$ proline, and $3 \%$ sodium selenite), T2 (1\% gibberellic acid, $8 \%$ zinc sulfate, potassium $76 \%$ di-hydrogen phosphate, $8 \%$ manganese sulfate, and $7 \%$ copper sulfate). 
Furthermore, for Xiangyaxiangzhan, T1 and T2 significantly increased Zn content in grains by $8.49 \%$ and $7.26 \%$, respectively while for Guixiangzhan, $4.83 \%$ and $5.25 \%$ higher grain Zn contents were recorded in T1 and T2, respectively (Fig. 2d). Grain Mn contents were improved in the grains of micro-nutrient treated rice plants. T1 led to $49.58 \%$ and $38.00 \%$ increased grain $\mathrm{Mn}$ contents in Xiangyaxiangzhan and Guixiangzhan, respectively, however, T2 was remained statistically similar to CK regarding grain Mn contents (Fig. 2e). Furthermore, for Xiangyaxiangzhan, T1 and T2 significantly increased grain $\mathrm{Cr}$ content by $129.11 \%$ and $45.18 \%$, respectively. Similarly, for Guixiangzhan, T1 and T2 significantly increased grain $\mathrm{Cr}$ content by $139.96 \%$ and $66.67 \%$, respectively. Further, T1 showed the highest grain Cr contents in both cultivars (Fig. 2f).

Table 3. Effect of exogenous micro-nutrient application on dry matter accumulation $\left(\mathrm{thm}^{-2}\right)$ in fragrant rice

\begin{tabular}{lllll}
\hline Rice cultivars & Treatment & 7 DAS & 14 DAS & 21 DAS \\
\hline Xiangyaxiangzhan & CK & $7.87 \mathrm{~b}$ & $9.66 \mathrm{~b}$ & $10.61 \mathrm{c}$ \\
& T1 & $8.91 \mathrm{a}$ & $11.86 \mathrm{a}$ & $12.93 \mathrm{a}$ \\
& T2 & $8.17 \mathrm{~b}$ & $10.08 \mathrm{~b}$ & $11.63 \mathrm{~b}$ \\
Guixiangzhan & CK & $7.80 \mathrm{~b}$ & $9.65 \mathrm{c}$ & $11.14 \mathrm{~b}$ \\
& T1 & $8.62 \mathrm{a}$ & $11.44 \mathrm{~b}$ & $12.42 \mathrm{a}$ \\
& T2 & $8.79 \mathrm{a}$ & $11.69 \mathrm{a}$ & $12.52 \mathrm{a}$ \\
\hline
\end{tabular}

Values sharing a letter in common within a column do not differ significantly according to LSD test at $\mathrm{P}<0.05$. CK (control); T1 (40\% zinc sulfate, $6 \%$ manganese sulfate, $1 \%$ ferric chloride, $50 \%$ proline, and $3 \%$ sodium selenite), T2 (1\% gibberellic acid, $8 \%$ zinc sulfate, potassium $76 \%$ di-hydrogen phosphate, $8 \%$ manganese sulfate, and $7 \%$ copper sulfate).

\section{Correlation analyses among 2-AP, micro-nutrients and grain quality attributes}

Correlation analyses showed significant positive correlations were among grain 2-AP, Se, $\mathrm{Zn}$ and $\mathrm{Cr}$ content in response to micro-nutrient application for both rice cultivars. Contrastively, significant negative correlations were noted among 2-AP, amylose, chalky rice percentage and chalkiness degree for both Xiangyaxiangzhan and Guixiangzhan. Furthermore, significant correlations were identified among 2-AP, Mn and protein content in response to micro-nutrient application for Xiangyaxiangzhan but not for Guixiangzhan. Significant correlations were also observed between $\mathrm{Zn}$ and $\mathrm{Cr}$ in response to exogenous nutrient application for both cultivars (Table 4). 
Table 4. Correlation relationship among grain 2-AP, micro-nutrient contents and quality traits of fragrant rice

\begin{tabular}{|c|c|c|c|c|c|c|c|c|c|c|}
\hline Index & $\begin{array}{l}\text { 2-AP } \\
\text { content }\end{array}$ & $\begin{array}{l}\mathrm{Se} \\
\text { content }\end{array}$ & $\begin{array}{l}\mathrm{Fe} \\
\text { content }\end{array}$ & $\begin{array}{l}\mathrm{Zn} \\
\text { content }\end{array}$ & $\begin{array}{l}\text { Mn } \\
\text { content }\end{array}$ & $\begin{array}{l}\mathrm{Cr} \\
\text { content }\end{array}$ & $\begin{array}{l}\text { PRO } \\
\text { content }\end{array}$ & $\begin{array}{l}\text { AMY } \\
\text { content }\end{array}$ & $\begin{array}{l}\text { CHA } \\
\text { Per }\end{array}$ & $\begin{array}{l}\text { CHA } \\
\text { Deg }\end{array}$ \\
\hline \multicolumn{11}{|c|}{ Xiangyaxiangzhan } \\
\hline 2-AP content & 1 & & & & & & & & & \\
\hline Se content & $0.931^{* *}$ & 1 & & & & & & & & \\
\hline Fe content & 0.564 & $0.745^{*}$ & 1 & & & & & & & \\
\hline Zn content & $0.908^{* *}$ & $0.798^{* *}$ & 0.307 & 1 & & & & & & \\
\hline Mn content & $0.799^{* *}$ & $0.963^{* *}$ & $0.797^{*}$ & 0.644 & 1 & & & & & \\
\hline Cr content & $0.937^{* *}$ & $0.999^{* *}$ & $0.717^{*}$ & $0.817^{* *}$ & $0.957^{* *}$ & 1 & & & & \\
\hline PRO content & $0.779^{*}$ & $0.949^{* *}$ & $0.819^{* *}$ & 0.645 & $0.983^{* *}$ & $0.939^{* *}$ & 1 & & & \\
\hline AMY content & $-0.824^{* *}$ & -0.575 & -0.075 & $-0.885^{* *}$ & -0.344 & -0.596 & -0.324 & 1 & & \\
\hline CHA Per & $-0.997^{* *}$ & $-0.934^{* *}$ & -0.560 & $-0.927^{* *}$ & $-0.807^{* *}$ & $-0.943^{* *}$ & $-0.788^{*}$ & $0.826^{* *}$ & 1 & \\
\hline CHA Deg & $-0.974^{* *}$ & $-0.892^{* *}$ & -0.602 & $-0.890^{* *}$ & $-0.752^{*}$ & $-0.897^{* *}$ & $-0.744^{*}$ & $0.829^{* *}$ & $0.978^{* *}$ & 1 \\
\hline \multicolumn{11}{|l|}{ Guixiangzhan } \\
\hline 2-AP content & 1 & & & & & & & & & \\
\hline Se content & $0.669^{*}$ & 1 & & & & & & & & \\
\hline Fe content & 0.470 & $0.914^{* *}$ & 1 & & & & & & & \\
\hline Zn content & $0.677^{*}$ & 0.578 & 0.439 & 1 & & & & & & \\
\hline Mn content & 0.408 & $0.936^{* *}$ & $0.968^{* *}$ & 0.466 & 1 & & & & & \\
\hline Cr content & $0.779^{*}$ & $0.982^{* *}$ & $0.880^{* *}$ & $0.680^{*}$ & $0.884^{* *}$ & 1 & & & & \\
\hline PRO content & 0.413 & $0.944^{* *}$ & $0.896^{* *}$ & 0.461 & $0.959^{* *}$ & $0.882^{* *}$ & 1 & & & \\
\hline AMY content & $-0.984^{* *}$ & -0.548 & -0.322 & -0.599 & -0.253 & -0.666 & -0.276 & 1 & & \\
\hline CHA Per & $-0.995^{* *}$ & $-0.677^{*}$ & -0.453 & -0.659 & -0.402 & $-0.780^{*}$ & -0.434 & $0.983^{* *}$ & 1 & \\
\hline CHA Deg & $-0.983^{* *}$ & -0.597 & -0.361 & -0.616 & -0.304 & $-0.704^{*}$ & -0.343 & $0.994^{* *}$ & $0.988^{* *}$ & 1 \\
\hline
\end{tabular}

Significant correlations at *P $<0.05$ and **P $<0.01$. PRO-Protein; AMY- Amylose; CHA Per- Chalky rice (\%); CHA Deg-Chalkiness degree. 


\section{Discussion}

This study explored the consequential affects foliar applied mixtures of micro-nutrients on the growth, yield, grain quality and accumulated grain nutrient contents in two fragrant rice cultivars i.e., Xiangyaxiangzhan and Guixiangzhan.

We have found that exogenous application of micro-nutrients significantly increased grain 2-AP, and other concentrations of other micro-nutrients i.e., $\mathrm{Se}, \mathrm{Fe}, \mathrm{Zn}, \mathrm{Mn}, \mathrm{Cr}$ in both Xiangyaxiangzhan and Guixiangzhan, however, mixture-II could not led to significant increase in grain $\mathrm{Fe}$ and $\mathrm{Mn}$ contents (Fig. 2 a-f). Further significant correlations were also identified among 2-AP, $\mathrm{Zn}$ and Se in both rice cultivars (Table 3). The accumulation of 2-AP, $\mathrm{Zn}$ and $\mathrm{Se}$ in response to micro-nutrient application suggested that there may be parallel activation of pathways leading to proline (the precursor of 2-AP) accumulation in response to micro-nutrient application in fragrant rice (Thimmaraju et al., 2005; Huang et al., 2012; Mo et al., 2015). In a recent study, Mo et al. (2016) concluded that exogenous Zn supplementation significantly improved 2 -AP contents in aromatic rice panicles.

Furthermore, Huang et al. (2012) found that glutamate dehydrogenase, a $\mathrm{Zn}$-containing enzyme present in the mitochondria, promotes the conversion of glutamate to proline and increases grain 2-AP content in fragrant rice. $\mathrm{Zn}$ mediates the biosynthesis of auxin plants, which could improve the chlorophyll contents and net photosynthetic rate in flag leaf, thus may may led to enhanced growth (Min et al., 2012). Additionally, application of $\mathrm{Zn}$ fertilizer could also promote the conversion of proline to 2-AP and increased the aroma of fragrant rice (Tang and $\mathrm{Wu}, 2006$ ). Se-supplementation has dynamic roles in the physio-morphological features and yield formation of rice Zhang et al. (2003). Se-related increase in 2-AP contents (significant correlations) might be the confirmation of the results of Zhou et al. (2005) who reported Se-induced up-regulation in proline accumulation which might be converted to 2-AP by the activation of proline dehydrogenase activities. Positive effects of Se on brown rice quality were also reported by Li et al. (2016). Moreover, Arvy (1995) found that Se concentration has synergistic effects on $\mathrm{Zn}$ content but not with $\mathrm{Fe}$, and $\mathrm{Mn}$ in Catharanthus roseus. Li (2016a) found that application of Fe fertilizer significantly increased Zn content in grains of rice. Recently, Li et al. (2016) reported positive effects of $\mathrm{Mn}$ application on growth, yield, quality and aromatic aspects of fragrant rice, whereas application of silicon ( $\mathrm{Si}$ ) in soil also led to increase in yield and aroma in fragrant rice (Mo et al., 2017). Additionally, we found significant correlations between grain 2-AP and $\mathrm{Cr}$ content in response to foliar applied micro-nutrients for both rice cultivars; however, the exact mechanisms between grain 2-AP and $\mathrm{Cr}$ content have not been known yet and needs further study.

We found significant effects of micro-nutrient application on the yield and related attributes in term of grain numbers per panicle, filled grain percentage, 1000-grain weigh and grain yield (Table 1). Moreover, exogenous micro-nutrient application also enhanced rice protein contents but reduced grain amylose, grain chalkiness and 
chalkiness \% (Table 2) as well as enhanced dry biomass accumulation in both rice cultivars (Table 3). Nutrient concentrations have significant roles in regulating the morphological growth and yield formation in rice (Abid et al., 2015) Previous studies have reported dynamic roles of micro-nutrient application on yield and quality of rice (Fang et al., 2008; Tian et al., 2009; Wu et al., 2010). Exogenous application of micro-nutrients increased grain numbers per panicle, seed setting rate and brown rice rate while decreased rice chalkiness (Fan et al., 2010). So, the results from this study revealed that mixed micro-nutrient application not only improved the rice grain mineral contents but also improved growth, yield and quality of rice. In addition, improved grain 2-AP contents in mixed micro-nutrient treated plants suggest that micro-nutrients might involve in 2-AP biosynthesis.

\section{Conclusion}

In short, exogenous application of mixed micro-nutrient has significant effects on yield and quality traits in fragrant rice, and led to enhanced grain aroma by improving grain 2-AP and mineral contents. These results further emphasized the importance of relationships among micro-nutrients especially $\mathrm{Zn}$, Se and 2-AP production in aromatic rice. Exploring these relationships and their involvement in rice aroma production has great potential for optimization of both trace elements enrichment aroma production and in fragrant rice cultivars.

Acknowledgements. This work was supported by National Natural Science Foundation of China (31271646), Natural Science Foundation of Guangdong Province (8151064201000017), and Agricultural Research Projects of Guangdong Province (2011AO20202001), Agricultural Standardization Project of Guangdong Province (4100F10003) and Guangzhou Science and Technology Plan Project (201707010413).

\section{REFERENCES}

[1] Abid, M., Khan, I., Mahmood, F., Ashraf, U., Imran, M., Anjum, S.A. (2015): Response of hybrid rice to various transplanting dates and nitrogen application rates.- Philippine Agricultural Scientist 98(1): 98-104.

[2] Arvy, M.P., Thiersault, M., Doireau, P. (1995): Relationships between selenium, micronutrients, carbohydrates and alkaloid accumulation in Catharanthus roseus Cells.J. Plant Nutrition 18(8):1535-1546.

[3] Ashraf, U., Kanu, A.S., Deng, Q., Mo, Z., Pan, S., Tian, H., Tang, X. (2017b): Lead (Pb) toxicity; physio-biochemical mechanisms, grain yield, quality, and pb distribution proportions in scented rice.- Frontiers in Plant Science 8: 1-17. doi: 10.3389/fpls.2017.00259

[4] Ashraf, U., Kanu, A.S., Mo, Z.W., Hussain, S., Anjum, S.A. Khan, I., Abbas, R.N., Tang, X.R. (2015): Lead toxicity in rice: effects, mechanisms, and mitigation strategies-a mini review.- Environmental Science and Pollution Research 22:18318-18332.

[5] Ashraf, U., Salim, M.N., Sher, A., Sabir, S.R., Khan, A., Pan, S.G., Tang, X.R. (2016): Maize growth, yield formation and water-nitrogen usage in response to varied irrigation 
and nitrogen supply under semi-arid climate.- Turkish Journal of Field Crops 21(1):87-95.

[6] Ashraf, U., Tang, X. (2017a): Yield and quality responses, plant metabolism and metal distribution pattern in aromatic rice under lead $(\mathrm{Pb})$ toxicity.- Chemosphere 176: 141-155.

[7] Bameri, M., Abdolshahi, R., Mohammadi-Nejad, G., Yousefi, K., Tabatabaie, S.M. (2012): Effect of different microelement treatment on wheat (Triticum aestivum) growth and yield.- International Research Journal of Applied and Basic Sciences 3(1): 219-223.

[8] Baradi, M.A.U., Martinez, N.G.T. (2015): 2-Acetyl-1-pyrroline levels in fragrant rice as affected by storage condition and packaging.- Philippine Agricultural Scientist 98(2):142-147.

[9] Buttery, R.G., Ling, L.C. Juliano, B.O., Turnbaugh, J.G. (1983): Cooked rice aroma and 2-acetyl-1-pyrroline.- Journal of Agriculture and Food Chemistry 31(4): 823-826.

[10] Champagne, E.T., Bett-Garber, K.L., Thompson, J., Mutters, R., Grimm, C.C., McClung, A.M. (2005): Effects of drain and harvest dates on rice sensory and physicochemical properties.- Cereal Chemistry 82(4): 369-374.

[11] Fan, J., Zheng, S.Z., Hu, H.Q., Zhuang, G.Q., Huang, Z.L. (2010): Primary Study on effect of different special foliar fertilizer application on the quality of rice and citrus.Hubei Agricultural Sciences 49(3): 553-557. (in Chinese)

[12] Fang, Y., Wang, L., Xin, Z.H., Zhao, L.Y., An, X.X., Hu, Q.H. (2008): Effect of foliar application of Zinc, Selenium, and Iron fertilizers on nutrients concentration and yield of rice grain in China.- Journal of Agriculture and Food Chemistry 56(6): 2079-2084.

[13] Habib, N., Akram, M., Javed, M., Azeem M., Ali Q., Shaheen, H., Ashraf, M. (2016): Nitric oxide regulated improvement in growth and yield of rice plants grown under salinity stress: antioxidant defense system.- Applied Ecology and Environmental Research 14(5) :91-105.

[14] Hu, B.L., Huang, D.R., Xiao, Y.Q., Fan, Y.Y., Chen, D.Z., Zhuang, J.Y. (2015): Mapping QTLs for mineral element contents in brown and milled rice using an Oryza sativa $\times O$. rufipogon backcross inbred line population.- Cereal Research Communications 2:1-12.

[15] Huang, Z.L., Tang, X.R., Wang, Y.L., Chen, M.J., Zhao, Z.K., Duan, M.Y., Pan, S.G. (2012): Effects of increasing aroma cultivation on aroma and grain yield of aromatic rice and their mechanism.- Scientia Agricultura Sinica 45(6):1054-1065 (in Chinese)

[16] Karanam, M. (2011): An improved protein extraction method for detecting ruminant material in feed using lateral flow device dipsticks.- Biotechnology Agronomy Society \& Environment 15:25-30.

[17] Li, M.J., Ashraf, U., Hua, T., Mo, Z.W., Pan, S.G., Duan, M.Y., Tang, X.R. (2016a): Manganese-induced regulations in growth, yield formation, quality characters, rice aroma and enzyme involved in 2-acetyl-1-pyrroline biosynthesis in fragrant rice.- Plant Physiology and Biochemistry 103:167-175.

[18] Li, Y., Li, Cheng, F.S. (2016): Effect of selenium enrichment on the quality of germinated brown rice during storage.- Food Chemistry 207:20-26.

[19] Maraval, I., Mestres, C., Pernin, K. Ribeyre, F., Boulanger, R., Guichard, E., Gunata, Z. (2008): Odor-active compounds in cooked rice cultivars from Camargue (France) analyzed by $\mathrm{GC}-\mathrm{O}$ and GC-MS.- Journal of Agriculture and Food Chemistry 56(13): 5291-5298.

[20] Maraval, I., Sen, K., Agrebi, A., Menut, C., Morere, A., Boulanger, R., Gay, F., Mestresa, C., Gunata, Z. (2010): Quantification of 2-acetyl-1-pyrroline in rice by stable isotope dilution assay through headspace solid-phase microextraction coupled to gas chromatography-tandem mass spectrometry.- Analytica Chimica Acta 675(2):148-155.

[21] Min, Y.L., Zheng, F.C., Chen, Y.C., Zhang, Y.G. (2012): The synthesis and characterization of $\mathrm{Zn}$-tryptophan complexes and their luminescence properties.- 
Journal of Material Science 23(5):1116-1121.

[22] Mo, Z., Huang, J., Xiao, D., Ashraf, U., Duan, M., Pan, S., Tian, H., Xiao, L., Zhong, K., Tang, X.R. (2016): Supplementation of 2-Ap, Zn and La improves 2-acetyl-1-pyrroline concentrations in detached aromatic rice panicles in vitro.- PloS one. 11(2): e0149523.

[23] Mo, Z., Li, W., Pan, S., Fitzgerald, T.L., Xiao, F., Tang, Y., Wang, Y., Duan, M., Tian, H., Tang, X.R. (2015): Shading during the grain filling period increases 2-acetyl-1-pyrroline content in fragrant rice.- Rice 8(1): 9. doi: 10.1186/s12284-015-0040-y.

[24] Mo, Z., Lei, S., Ashraf, U., Khan, I., Li, Y., Pan, S., Duan, M., Tian, H., Tang, X. (2017): Silicon fertilization modulates 2-acetyl-1-pyrroline content, yield formation and grain quality of aromatic rice. -Journal of Cereal Science 75:17-24.

[25] Pandey, R., Krishnapriya, V., Bindraban, P.S. (2014): Biochemical nutrient pathways in plants applied as foliar spray: phosphorus and iron. - Washington, DC, USA.

[26] Saleem, M.F., Bilal, M.F., Awais, M., Shahid, M.Q., Anjum, S.A. (2010): Effect of nitrogen on seed cotton yield and fiber quality of cotton (Gossypium hirsutum L.).Journal of Animal and Plant Sciences 20:23-27.

[27] Sun, S., Liu, S. (1991): Study of the effects of nitrogen and zinc fertilizers on the aroma of rice.- Acta Agronomica Sinica 17(6):430-435.

[28] Tang, X.R., Wu, L. (2006): Effect of application of Zinc, Iron and Lanthanum on contents of aroma in brown rice and proline in flag leaf of aromatic rice.- Hybrid Rice 21(6):69-72. (in Chinese)

[29] Thimmaraju, R., Bhagyalakshmi, N., Narayan, M.S., Venkatachalam, L., Ravishankar, G.A. (2005): In vitro culture of Pandanus amaryllifolius and enhancement of 2-acetyl-1-pyrroline, the major flavouring compound of aromatic rice, by precursor feeding of L-proline.- Journal of Science of Food and Agriculture 85(15):2527-2534.

[30] Tian, H., Li, G.X., Yuan, H.M., Zhong, K.Y., Duan, M.Y., Wu, L., Tang, X.R. (2009): Studies on the cultivation techniques characterized by enhancing source, activating sink and improving quality for double-cropping super rice II. Effects of a rice quality promoter on source, sink and grain quality.- Hybrid Rice 24(1): 78-81. (in Chinese)

[31] Widjaja, R., Craske, J.D., Wootton, M. (1996): Comparative studies on volatile components of non-fragrant and fragrant rices.- Journal of the Science of Food Agriculture 70(2):151-161.

[32] Wu, L., Kang, L., Tang, X.R., Li, G.X., Tian, H., Duan, M.Y. (2010): Studies on the cultivation techniques characterized by enhancing source, activating sink and improving quality for double-cropping super rice IV. Theory and Technology.- Hybrid Rice 25(3): 74-78. (in Chinese)

[33] You Z.L., Xiao, D.Y., Mei, E.W., Qing, S.Z. (2012): Effects of lodging at different filling stages on rice yield and grain quality.- Rice Science 19(4):315-319. (in Chinese)

[34] Zain, M., Khan, I., Qadri, R.W.K. (2015): Foliar application of micronutrients enhances wheat growth, yield and related attributes.- American Journal of Plant Science 6(7):864-869.

[35] Zhang, C., Wu, Y.Y., Peng, Z.K., Zhou, D.Z. (2003): The influence of selenium on pro and MDA contents of rape seedling stage.- Hubei Agriculture Sciences 2: 45-47. (in Chinese)

[36] Zhang, M., Tang, S., Huang, X., Zhang, F., Pang, Y., Huang, Q., Yi, Q. (2014): Selenium uptake, dynamic changes in selenium content and its influence on photosynthesis and chlorophyll fluorescence in rice.- Environmental and Experimental Botany 107: 39-45.

[37] Zhou, D.Z., Tang, Q.Y., Zhang, C., Wu, Y.Y. (2005): Effects of selenium on the contents of chlorophyll, proline and malondialdehyde in the seedlings of cauliflower.- Hubei Agricultural Sciences 2:77-78. (in Chinese) 